\title{
A Model for Prediction of Temperature in Steel Structure Protected by Intumescent Coating, based on Tests in the Cone Calorimeter
}

\author{
YONG WANG ${ }^{1}$, ULF GÖRANSSON ${ }^{2}$, GÖRAN HOLMSTEDT ${ }^{2}$, and \\ ALAA OMRANE ${ }^{3}$ \\ ${ }^{1}$ University of Manchester, UK \\ ${ }^{2}$ Department of Fire Safety Engineering \\ Lund University, Sweden \\ ${ }^{3}$ Division of Combustion Physics \\ Lund University, Sweden
}

\begin{abstract}
Intumescent coating is an important fire protection method for steel structures. Traditionally its fire properties have been evaluated by performing furnace tests using a standardized test procedure and following a standardized time-temperature curve. This procedure is restrictive in performance based fire safety engineering design since it limits the fire condition to the standard one only. In this paper, a model is outlined that can take into account the different fire protection abilities of intumescent coating that will occur depending on what type of fire the coating is subjected to. The model is based on a experimental study, containing about 50 tests, performed in the Cone Calorimeter. Some test results are presented as well as an analysis model of the test results.
\end{abstract}

KEYWORDS: intumescent coating, conductivity, Cone Calorimeter, model

\section{NOMENCLATURE}

$\begin{array}{ll}c & \text { Specific heat }(\mathrm{J} / \mathrm{kgK}) \\ d & \text { Thickness }(\mathrm{m}) \\ h & \text { Heat transfer coefficient }\left(\mathrm{W} / \mathrm{m}^{2} \mathrm{~K}\right) \\ k & \text { Conductivity }(\mathrm{W} / \mathrm{mK}) \\ Q & \text { Heat flow }\left(\mathrm{W} / \mathrm{m}^{2} \mathrm{k}\right) \\ t & \text { Time }(\mathrm{s}) \\ T & \text { Temperature }(\mathrm{K}) \\ \Delta T_{s} & \text { Temperature increase }(\mathrm{K})\end{array}$

$\begin{array}{ll}\text { Greek } & \\ \varepsilon & \text { Emissivity } \\ \sigma & \text { Stefan Bolzmann } \\ \text { Subscripts } \\ p & \text { Paint } \\ s & \text { Steel } \\ a & \text { Ambient } \\ 1 & \text { Surface } \\ e & \text { External } \\ r a d & \text { Radiation } \\ c & \text { Convective }\end{array}$

\section{INTRODUCTION}

Intumescent coating has a number of advantages (e.g., attractive architectural appearance, lightweight and thin) over other forms of fire protection such as boards and spray, and is becoming more widely specified as the fire protection material of different types of construction. Its main feature is that at high temperatures, the chemical components in intumescent coating react to cause the intumescent coating to expand many times its original thickness, thus providing the necessary insulation to delay temperature rise in the protected construction material preventing it from rising to a critical level. The chemical reactions are not only temperature dependent, but they may also be dependent on heat 
flux to the intumescent coating. Therefore, unlike other conventional fire protection materials whose thermal properties are mainly temperature dependent only, characterizing the thermal properties of intumescent coating will need to take into consideration the level of heat flux.

This could potentially deter intumescent coating from being used in applications involving the so-called "natural fire condition" in building construction. At present, building fire resistance design is largely based on the "standard fire condition," under which the fire temperature - time relationship follows only one prescribed standard relationship, most often given in ISO 834 (1975). Since the standard fire exposure temperature-time relationship is fixed, performance of an intumescent coating can be quantified by conducting a relatively small number of standard fire tests. In contrast, the temperature - time relationship of a natural building fire condition is not fixed, but varies according to such factors as the amount of combustible materials inside a building enclosure, ventilation condition and construction lining materials. EN 1991-1-2 (2002) provides a method to evaluate temperature - time relationships of natural fires. With an infinite array of fire temperature - time curves, it is clearly not possible to conduct experiments on intumescent coating to cover all natural fire conditions. Extrapolation of fire test results becomes necessary if natural fire conditions are to be considered in fire engineering design, which is becoming the trend with the publication of design documents such as EN 1991-1-2 (2002). For intumescent coating to be considered in such applications, it is necessary to resolve the issue of how to reliably predict thermal properties of intumescent coating under natural fire conditions.

In practical heat transfer calculations, the required thermal properties include the material thermal conductivity, density and specific heat. Using intumescent coating as fire protection, since the amount of fire protection material involved is very small compared to the protected construction, heat storage inside the intumescent coating may be considered to be negligible. Consequently, its mass and specific heat may be considered to be constant and independent of temperature and heat flux. The main problem is how to determine the thermal conductivity of intumescent coating.

EN 13381-4 (2002) has a well-established procedure to calculate thermal conductivity of fire protection materials from the standard fire resistance test results. It would be advantageous if any method to determine the thermal conductivity of intumescent coating is to be based on this existing method. This would ultimately involve a large number of fire tests under both the standard and natural fire conditions. The present paper will report the results of an interim study, which gives the results of an experimental study of intumescent coating protected steel plates under cone calorimeter and the analysis of the test results. The main objectives of this interim study are:

1 to investigate the effects of various factors on the temperature and thus the thermal conductivity of intumescent coating, the factors including steel plate thickness, number of layers of intumescent coating and level of cone incident irradiance;

to assess whether it is possible to develop a single thermal conductivity temperature relationship for applications under different levels of heat flux to intumescent coating; and

3

to suggest a method to investigate how to link thermal conductivity obtained from the standard fire exposure to applications under design natural fires. 


\section{EXPERIMENTAL INVESTIGATION}

A large number of tests have been performed in a Cone Calorimeter set-up. The tests did not follow the standard method in ISO 5660 (2002) as the electrical cone heater used had a diameter double the size of the standard ISO 5660 (2002) cone heater and the distance from the lower part of the cone to the sample surface was initially $100 \mathrm{~mm}$.

The incident irradiance was 35,50 and $65 \mathrm{~kW} / \mathrm{m}^{2}$ as measured where the sample surface was in the beginning of the test. The test samples were steel plates of size $100 \mathrm{~mm}$ by $100 \mathrm{~mm}$ having thicknesses 5,10 or $20 \mathrm{~mm}$. The samples were painted with an intumescent coating (Char 21, supplied by KBS Brandskydd AB) applied in 1, 2 or 3 layers. Each layer contained $10 \mathrm{~g}$ of wet paint, corresponding to approximately $7.2 \mathrm{~g}$ of dry coating or 0.4-0.5 mm of dry film thickness (DFT).

During the tests the temperature of the steel plate was measured by three to five thermocouples that were welded on to the backside surface of the steel plate. The temperatures measured by the different thermocouples did not vary by more than one or two centigrade, which suggests that the steel temperatures could be given as a mean steel temperature over the surface. Furthermore, an auxiliary test on the $20 \mathrm{~mm}$ thick plate was performed to confirm that the steel plate temperature was uniform throughout its thickness. The backside of the steel plate was supported by mineral wool. In order to help obtain the heat loss from the steel plate to the mineral wool, the mineral wool temperature was measured at $20 \mathrm{~mm}$ from the backside of the steel plate. The varying height of the test samples were measured by an ICCD camera in some tests and by visual observations in some tests. In some of the tests, the coating surface temperature was measured by means of thermographic phosphors using the technique to be described below. Figure 1 shows the experimental set-up. Phosphor particles, $\mathrm{Mg}_{3} \mathrm{FGeO}_{4}$ : $\mathrm{Mn}$, were seeded on the exposed surface area of the test specimen with a covering area of around $0.5 \mathrm{~cm}^{2}$.

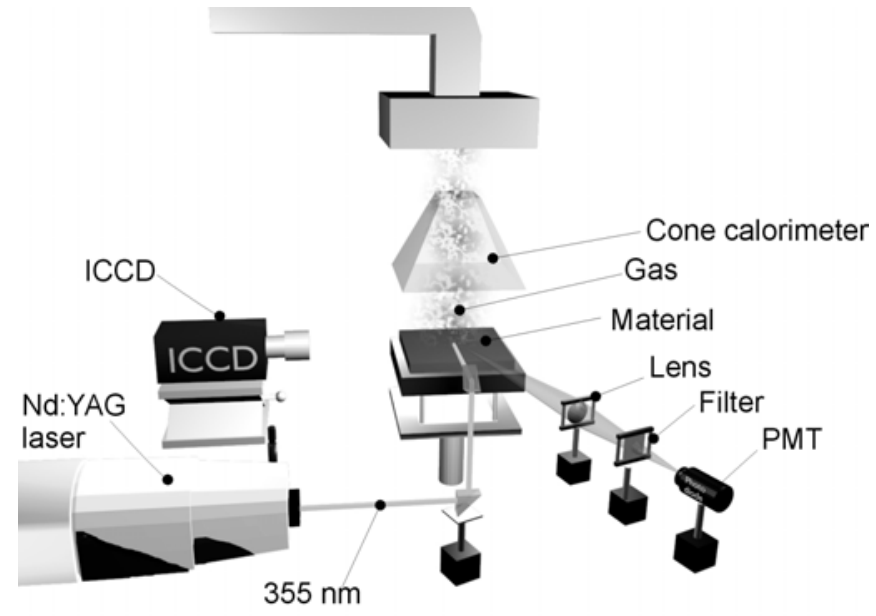

Fig. 1. Experimental setup: laser device.

An Nd:YAG pulsed laser was used to excite the seeded thermographic phosphors on the exposed surface of the test specimen under the cone calorimeter hood. At an angle from the excitation path, the subsequent emission was detected by a photomultiplier (PMT) through an optical lens and an interference filter. An oscilloscope was used to digitize 
and transfer the PMT signal to a personal computer. The data was processed afterwards to get the emission lifetime and hence the coating surface temperature.

Using the optical technique described above, the thickness of the expanding intumescent coating could also be monitored during the experiment. For this purpose an ICCD camera was used to take snapshots of the material. The camera was triggered externally from the laser to register the thickness variation and the spatial position of the phosphor particles. From information of pixel variations and grid with a known size, the thickness of the expanding coating was obtained.

\section{THEORETICAL ANALYSIS}

The objective of the theoretical study is to extract the thermal conductivity of the intumescent coating material from the cone test results. Figure 2 shows a sketch of the materials under the cone calorimeter. The thermal conductivity of the intumescent coating material may be obtained from the following equation:

$k_{p}\left(\frac{T_{1}-T_{S}}{d_{p}}\right)-Q_{\text {loss }}=\frac{\Delta T_{S}}{\Delta t} C_{s} \rho_{S} d_{S}$

Either the original thickness or the expanded thickness may be used. If the original thickness is used, the thermal conductivity obtained from Eq. 1 will be referred to as the effective thermal conductivity. If the expanded thickness is used, the thermal conductivity will be referred to as the apparent thermal conductivity. In order to solve the above equation, it is necessary to obtain $Q_{\text {loss }}$ and $T_{1}$.

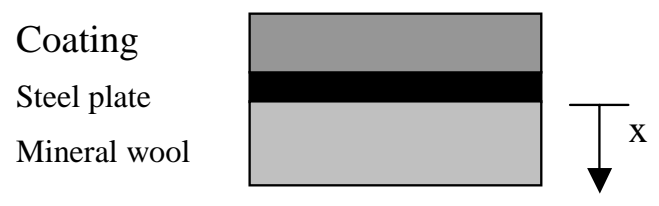

Fig. 2. Model of analysis.

$Q_{\text {loss }}=k_{w} \frac{d T_{w}}{d x}$

$Q_{\text {loss }}$ is evaluated at the top of the mineral wool. In the cone calorimeter test, the mineral wool temperature was measured at only one location, being $20 \mathrm{~mm}$ from the backside of the steel plate. A numerical thermal analysis would be necessary to determine the temperature distribution in the mineral wool, using the steel temperature as the boundary condition. Alternatively, the mineral wool slab may be considered a semi-finite slab, for which an analytical solution is given by Carslaw \& Jaeger (1959). The alternative approach has been adopted in this research. To calculate temperature on the surface of the intumescent coating, the following heat balance equation may be used:

$\varepsilon \sigma T_{1}^{4}+h_{c}\left(T_{1}-T_{\infty}\right)=Q_{e}-Q_{\text {loss }}-\frac{\left(\Delta T_{1}+\Delta T_{S}\right)}{2 \Delta t} \rho_{p} C_{p} d_{p}-\frac{\Delta T_{s}}{\Delta t} C_{s} \rho_{s} d_{s}$ 
The above equation is translated into the following statement:

Radiant heat loss from the surface of the intumescent coating + convective heat loss from the surface of the intumescent coating = Cone incident irradiance on the test sample surface - conductive heat loss from the backside of the steel plate to the mineral wool heat stored in the intumescent coating - heat stored in the steel plate

For this research, $h_{c}$ has a constant value of $20 \mathrm{~W} /\left(\mathrm{m}^{2} . \mathrm{K}\right)$ and the surface emissivity of the intumescent coating $\varepsilon$ is 0.92 (Bartholmai et al 2002). The intumescent coating temperature is taken as the average value of its exposed surface temperature and the steel temperature. Also in this research, the intumescent coating is assumed to have a nominal density of $1000 \mathrm{~kg} / \mathrm{m}^{3}$ and specific heat of $1000 \mathrm{~J} /(\mathrm{kg} . \mathrm{K})$. Since the heat stored in the intumescent coating is extremely small, it is not necessary to use very accurate values of intumescent coating temperature, density and specific heat.

\section{RESULTS AND DISCUSSION}

Equation 1 contains two undetermined variables, the heat loss $\left(Q_{\text {loss }}\right)$ by conduction to the mineral wool on the backside of the steel plate and the intumescent coating surface temperature $T_{1}$. It is not possible to measure the heat conduction from the backside of the steel plate to the mineral wool. Attempt was made to measure the intumescent coating surface temperature using the laser technique described. However, because of expansion and swelling of intumescent coating, the phosphor particles that were seeded on the coating surface disappeared in many tests. Therefore, a decision was made to calculate the values of these two values and then assess validity of these calculations by checking the predicted intumescent surface temperatures with laser measurements wherever possible and to check the calculated mineral wool temperatures.

Figure 3 presents a typical comparison between the measured and predicted intumescent coating surface temperatures. It can be seen that within a relatively short period of cone exposure, both the measured and predicted intumescent coating surface temperatures increase rapidly to a steady temperature value.

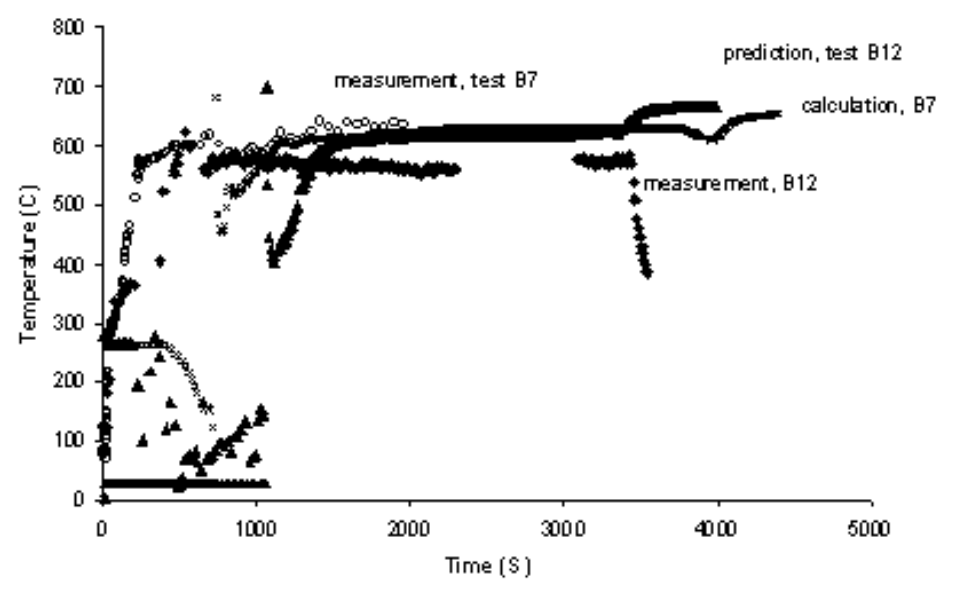

Fig. 3. Comparison between predicted and calculated coating surface temperature. 
Figure 4 shows a typical breakdown of the terms on the right hand side of Eq. 3. It can be seen that at the steady coating surface temperature, the cone incident irradiance $\left(Q_{e}\right)$ is much greater than the combined value of the other three terms, designated as the conductive heat loss $\left(Q_{\text {loss }}\right)$, the heat stored in the intumescent coating $\left(C_{p} \rho_{p} d_{p}\left(\Delta T_{1}\right.\right.$ $\left.\left.+\Delta T_{s}\right) / 2 \Delta t\right)$ and in the steel plate $\left(C_{s} \rho_{s} d_{s} \Delta T_{s} / \Delta t\right)$.

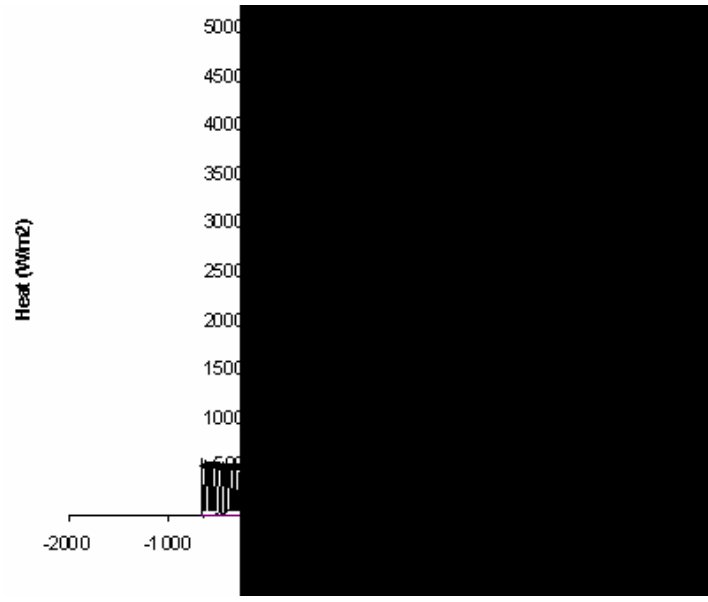

Fig. 4. Heat loss - time relationship, $20 \mathrm{~mm}$ steel, $50 \mathrm{~kW} / \mathrm{m}^{2}$.

In other words, the approximate solution to $T_{1}$ may be obtained by neglecting the three terms with minus sign on the right hand side of Eq. 3. Substituting the assumed values of $\varepsilon=0.92$ and $h_{c}=20 \mathrm{~W} /\left(\mathrm{m}^{2} . \mathrm{K}\right)$ into Eq. $1, T_{1}$ is approximately $630^{\circ} \mathrm{C}$ if the incident irradiance of the cone calorimeter is constant at $50 \mathrm{~kW} / \mathrm{m}^{2}$. The difference between the predicted surface temperature and the laser measured coating surface temperature is quite large, the maximum being about $20 \%$. When calculating the thermal conductivity of the intumescent coating using Eq. 1, the difference $\left(T_{1}-T_{s}\right)$ between the intumescent coating surface temperature and the measured steel plate temperature is used. Therefore, the difference in this value $\left(T_{1}-T_{s}\right)$ between using the predicted and laser measured intumescent surface temperatures would be greater. This study has, however used the predicted intumescent coating surface temperature to calculate the intumescent coating thermal conductivity.

If the difference in conductive heat loss is linearly related to the difference in predicted and measured mineral wool temperatures, a relatively large maximum difference of about $30 \%$ would translate into a difference of less than $10 \%$ in the total heat terms (hence the calculated thermal conductivity) in Eq. 1. As will be shown later, this level of inaccuracy will be overwhelmed by a number of other factors of uncertainty and the calculated mineral wool temperatures are considered to be acceptable.

\section{Effective Thermal Conductivity}

As previous mentioned, the effective thermal conductivity is obtained by setting the coating thickness in Eq. 1 to the initial value. Figures 5-6 compare the effective thermal conductivity - temperature relationships with different steel plate thicknesses for 1 , 2 , and 3 layers of intumescent coating. The intumescent coating temperature is taken as 
the average value of the steel plate temperature $\left(T_{s}\right)$ and the calculated intumescent coating surface temperature $\left(T_{1}\right)$. It can be seen that the effective thermal conductivity starts to drop sharply after the intumescent coating temperature has reached approximately $250^{\circ} \mathrm{C}$, which may be taken as the reaction temperature of this type of intumescent coating. Before this reaction, the intumescent coating is hardly effective so that the calculated thermal conductivity is very high and subject to wild fluctuations. The calculated effective thermal conductivity values become more stable after the intumescent coating has reached about $350^{\circ} \mathrm{C}$ when the intumescent coating would have been almost fully effective throughout its thickness. Therefore, discussions below will focus on the stable value of intumescent coating thermal conductivity because it is during this stage that the intumescent coating is the most effective in providing insulation to the protected steel plate.

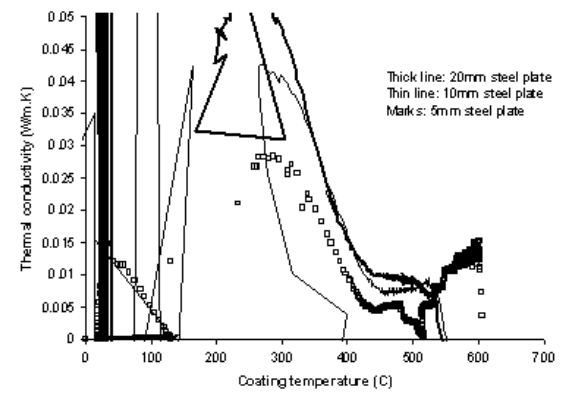

Fig. 5. Effective thermal conductivity, $50 \mathrm{~kW} / \mathrm{m}^{2}$, DFT=0,4 mm.

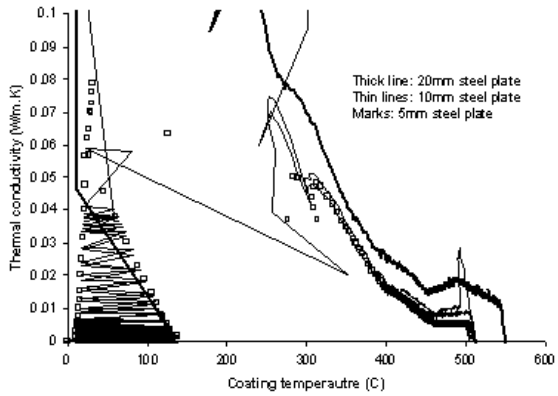

Fig. 6. Effective thermal conductivity, $50 \mathrm{~kW} / \mathrm{m}^{2}$, DFT=1,2 mm.

Figures 7-8 compare the effective thermal conductivity - temperature relationships with different layers of intumescent coating for steel plate thickness of $5 \mathrm{~mm}$ and $20 \mathrm{~mm}$ respectively. The effect of the number of layers of intumescent coating is not as great as the effect of different steel plate thickness.

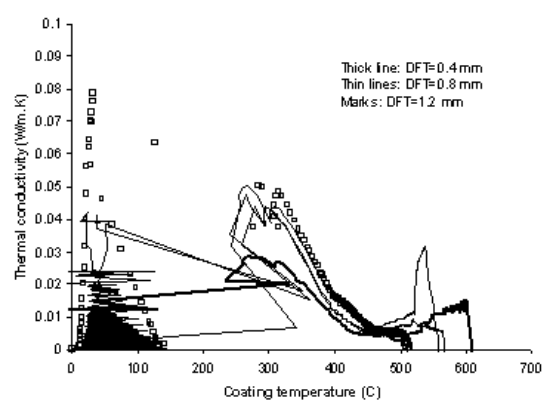

Fig. 7. Effective thermal conductivity, $50 \mathrm{~kW} / \mathrm{m}^{2}, 5 \mathrm{~mm}$ steel plate.

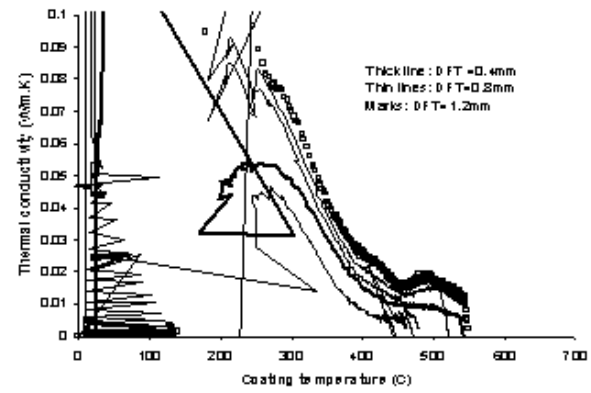

Fig. 8. Effective thermal conductivity, $50 \mathrm{~kW} / \mathrm{m}^{2}, 20 \mathrm{~mm}$ steel plate.

The calculated intumescent coating effective thermal conductivity values are within a relatively narrow band.

Figure 9 compare the effective thermal conductivity - temperature relationships for nominally identical test specimens (same steel plate thickness and number of layers of intumescent coating) but under different levels of cone irradiance of 35 and $65 \mathrm{~kW} / \mathrm{m}^{2}$ for 1 to 3 layers of intumescent coating respectively. The steel plate thickness was $10 \mathrm{~mm}$. 
For these tests, there was good repeatability between nominally identical tests. However, there are large differences in effective thermal conductivity between different levels of cone incident irradiance. All figures show that the thermal conductivity is higher at a higher cone irradiance. This may be explained by the fact that a higher irradiance gives less time for the intumescent coating to react fully, therefore being less effective, which leads to a higher effective thermal conductivity.

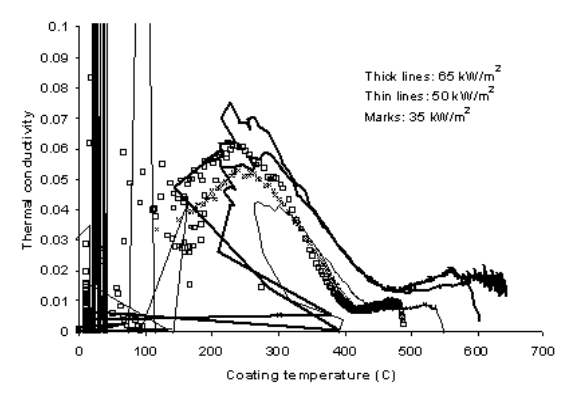

Fig. 9. Effective thermal conductivity, $\mathrm{DFT}=0,4 \mathrm{~mm}$.

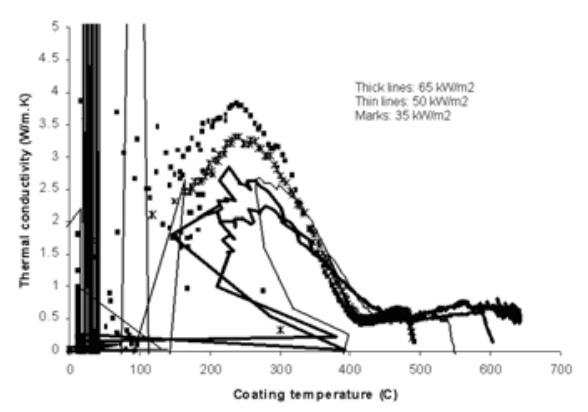

Fig. 10. Apparent thermal conductivity, $\mathrm{DFT}=1,2 \mathrm{~mm}$.

From the above discussions, it becomes clear that there is a large amount of scatter in the predicted effective thermal conductivity-temperature relationships under different conditions. This makes it impossible to use only one effective thermal conductivitytemperature relationship to represent all cases. Also it is worthwhile to point out that because the behavior of intumescent coating in fire is complex, it is extremely difficult to accurately estimate its behavior. This suggests that the behavior of intumescent coating in fire is affected by many yet to be understood factors. Nevertheless, because of the need to predict thermal performance of intumescent coating protected steel structures under natural fire conditions and the impossibility of conducting testing to cover all natural fire conditions, a practical means has to be made available to obtain the thermal conductivity of intumescent coating. The goal of such a study can only be about finding a simple means to predict the thermal conductivity of intumescent coating as accurately as can be practically accepted.

Clearly, temperature is not the only factor that affects the calculated effective thermal conductivity of intumescent coating, otherwise, the effective thermal conductivity temperature relationships of different tests would be similar. One other possible factor is the expansion thickness. This is based on the assumption that after expanding to become effective, the internal construction of the expanded intumescent coating should be similar to give similar thermal conductivity, but other factors (such as the protected steel thickness, the number of layers and the incident cone irradiance) make the intumescent coating expand differently. If the expanded intumescent coating thickness is used in Eq. 1, the thermal conductivity so obtained may be called apparent thermal conductivity. The objective of the following section is to find out whether the scatter in apparent thermal conductivity is less than that in effective thermal conductivity. The apparent thermal conductivity is easily obtained by multiplying the effective thermal conductivity by the rate of expansion of the coating. The final expanded coating thickness will be used to calculate the apparent thermal conductivity. Figure 10 shows the calculated apparent thermal conductivity for a three-layer paint, $10 \mathrm{~mm}$ steel at different irradiance. 


\section{Expansion Rate}

Bearing in mind the difficulty of obtaining accurate information on thermal conductivity of even conventional fire protection materials, it appears that the scatter using apparent thermal conductivity of intumescent coating is practically acceptable. On this assumption, it is now necessary to obtain the expansion rate of intumescent coating. Since the objective of this research is to find a relatively simple way of estimating the thermal conductivity of intumescent coating, the method to obtain the expansion rate of intumescent coating should not be complex and elaborate. A relatively simple theory (Henderson et al 1985) for expansion rate of intumescent coating is to relate it to the final expansion rate and its density by a power function. However, this model is still not practical to use as it would be necessary to evaluate a number of empirical constants under different conditions. As mentioned previously, the final expanded thickness should be used to calculate apparent thermal conductivity of intumescent coating. Provided the time to heat exposure of intumescent coating is sufficiently long, the final expanded thickness will be reached. In realistic applications, should a fire exposure be short so as not to cause the intumescent coating to fully expand. This fire exposure is unlikely to be severe to cause any noticeable damage to the protected structure and may not be considered. Therefore, in a practical method to determine the thermal conductivity of intumescent coating, it is acceptable to use only the final expanded coating thickness.

\section{PROPOSED METHOD TO CALCULATE APPARENT THERMAL CONDUCTIVITY}

With the apparent thermal conductivity, it is possible to use only one thermal conductivity - temperature relationship for different steel plate thickness, initial coating thickness and level of incident cone irradiance. The calculations are based on the final expanded coating thickness on which steel plate thickness, initial coating thickness and level of incident cone irradiance all have clear influence. A practical method of predicting temperatures in intumescent coating protected steel structure for applications under natural fire conditions emerges. The following is an outline procedure of this method.

Step 1: Conduct cone calorimeter tests of the coating product under different incident cone irradiance, using different steel plate and intumescent coating thicknesses.

Step 2: Carry out a regression analysis to establish the approximate relationship of final coating thickness as a function of steel plate thickness, intumescent coating thickness and level of incident cone irradiance. For one type of intumescent coating product this needs to be performed only once. The remaining steps are followed for predicting steel temperatures under the standard fire condition so that there is not much additional work for applications under the natural fire condition.

Step 3: Conduct standard fire resistance tests and follow the procedure in EN 13381-4 to extract the effective thermal conductivity-temperature relationship of the coating product. Also measure the final coating thickness. The apparent thermal conductivity under the standard fire condition is obtained by multiplying the effective thermal conductivity by the expansion ratio under the standard fire condition.

Step 4: Using the regression equation from step 2 and the measured final coating thickness from step 3, calculate the equivalent constant level of heat flux on the coating product under the standard fire exposure for the product. 
Step 5: Calculate the equivalent constant level of heat flux of the natural fire condition which is related to the initial rate of temperature increase of the fire. Since the initial tangent of a natural fire temperature-time relationship is highly sensitive to how the initial fire temperature-time relationship is plotted, the secant rate of temperature increase of the fire may be used. The equivalent constant level of heat flux of the design natural fire condition is obtained by multiplying the standard fire exposure by the ratio of the secant rate of temperature increase of the design natural fire condition to that of the standard fire exposure.

Step 6: Using the equivalent constant level of heat flux under the natural fire condition from step 5 and the regression equation from step 2, find the final expansion rate under the natural fire condition.

Step 7: The effective thermal conductivity of the intumescent coating under the natural fire condition is obtained by dividing the apparent thermal conductivity under the standard fire condition from step 3 by the final expansion rate under the natural fire condition obtained from step 7.

Step 8: The temperature in the intumescent coating protected steel exposed to the natural fire is calculated using the effective thermal conductivity and the initial coating thickness.

\section{CONCLUSIONS}

This report has presented the results of a study of the behavior of intumescent coating under cone calorimeter. The objective of this exercise was to assess whether it would be possible to predict temperature rises in intumescent coating protected steel under design natural fire conditions by using test results from the same system under the standard fire exposure. The cone tests were performed for three different thicknesses of steel plates $(5,10$, and $20 \mathrm{~mm}), 1,2$, or 3 layers of intumescent coating and under three levels of incident cone irradiance: $35 \mathrm{~kW} / \mathrm{m}^{2}, 50 \mathrm{~kW} / \mathrm{m}^{2}$ and $65 \mathrm{~kW} / \mathrm{m}^{2}$. In each test, temperatures were measured in the steel plate and in the mineral wool on the backside of the steel plate. In some tests, the coating surface temperature was measured using a laser device and the expansion of intumescent coating measured either manually or by the laser device. A theoretical model was developed to extract thermal conductivity of intumescent coating for all the tests. This theoretical model used the measured steel plate temperature as input data and also predicted the mineral wool temperature, the intumescent coating surface temperature and the thermal conductivity of the intumescent coating. From the results of this study, the following conclusions may be drawn:

1. The mineral wool temperature has relatively miner influence on the calculated thermal conductivity of intumescent coating. The theoretical model predicted mineral wool temperatures in good agreement with the test results so that accuracy of the calculated thermal conductivity is unlikely to be affected by this calculation.

2. Wherever measurements of intumescent coating surface temperature were available, the model predictions were in good qualitative agreement with the laser measurements and in reasonable quantitative agreement. The predicted and measured coating surface temperatures rose quickly initially and then stayed almost constant during the remaining long fire exposure. The predicted coating surface temperature was about $630^{\circ} \mathrm{C}$ and the measured values ranged from $530^{\circ} \mathrm{C}$ to $630^{\circ} \mathrm{C}$. The difference in surface temperature may lead to about $35 \%$ under 
prediction in the calculated thermal conductivity. In this study, calculations of thermal conductivity were performed by using the predicted coating surface temperature.

3. There are large scatters in the calculated thermal conductivity - temperature relationships. However, the scatter in effective thermal conductivity, which was obtained by using the initial intumescent coating thickness in Eq. 1, was much greater than in apparent thermal conductivity, which was obtained by using the final intumescent coating thickness in Eq. 1. Overall, the scatter in effective thermal conductivity is about $50 \%$ higher than in apparent thermal conductivity.

4. Using the ratio of the maximum steady value of thermal conductivity to the minimum value to represent the scatter in different thermal conductivity temperature relationships, the overall scatter value for all the tests was 3.81 for effective thermal conductivity and 2.59 for apparent thermal conductivity.

5. If the scatter in apparent thermal conductivity in (4) is considered to be practically acceptable, it is possible to extrapolate the apparent thermal conductivity of intumescent coating based on the standard fire resistance tests to predict temperatures in intumescent coating protected steel structures under different design fire situations. A method has been suggested, but implementation of this method awaits more comprehensive research studies for validation and for establishing a database of intumescent coating final expansion rate under cone calorimeter tests.

\section{ACKNOWLEDGEMENTS}

This study was performed in the Fire Safety Engineering Department, Lund University, Sweden with partial financial support from the Wenner-Gren Foundation of Sweden and from the European Community through a Large Scale Facility grant to the Combustion Centre of Lund University under the European Commission Contract No HPRI-CT-200100166. The intumescent coating was supplied by KBS Brandskydd AB free of charge.

\section{REFERENCES}

[1] Bartholmai, M., Schriever, R. and Schartel, B., "Influence of External Heat Flux and Coating Thickness on the Thermal Insulation Properties of Two Different Intumescent Coatings Using Cone Calorimeter and Numerical Analysis,” Fire and Materials, 27, 2002, pp. 151-162.

[2] Carslaw, H.S., and Jaeger, J.C., Conduction of heat in solids, $2^{\text {nd }}$ edition, Oxford University Press, 1959.

[3] EN 1991-1-2: "Actions on Structures - Part 1.2: General Actions - Actions on Structures Exposed to Fire,” Comité Européen de Normalisation, Brussels ,2002.

[4] ENV 13381-4: "Test Methods for Determining the Contribution to the Fire Resistance of Structural Members - Part 4: Applied Protection to Steel Members,” Comité Européen de Normalisation, Brussels, 2002.

[5] Henderson, J.B., Wiebelt, J.A., and Tant, M.R., "A Model for the Thermal Response of Polymer Composite Materials with Experimental Verification," Journal of Polymer Materials, 19, 1985, pp. 579-595. 
[6] ISO 834: "Fire Resistance Tests: Elements of Building Construction," International Organization for Standardization, Geneva, 1975.

[7] ISO 5660-1, "Reaction-to-fire Tests: Heat Release, Smoke Production and Mass Loss Rate,” International Organization for Standardization, Geneva, 2002. 